\title{
UNIDADES DE CONSERVAÇÃO E PROCESSOS EM EDUCAÇÃO AMBIENTAL
}

\author{
Maíra Arantes Leite Wick ${ }^{1}$ \\ Luciano Fernandes Silva ${ }^{2}$
}

Resumo: Objetivou-se com esta investigação compreender o processo de inserção e de estruturação da educação ambiental (EA) em Unidades de Conservação (UC), particularmente no Parque Estadual do Jaraguá, da Cantareira e da Serra do Mar. Neste trabalho apresentamos dados que buscam responder a questões específicas de pesquisa, relacionadas às perspectivas da EA identificadas nos planos de manejo e das atividades de EA planejadas e organizadas pelos três parques estaduais. As análises indicam que a EA estruturada em UC reflete a existência de uma preocupação vinculada mais às questões ambientais do que necessariamente às questões educativas, cuja finalidade é promover a valorização dessas áreas enquanto locais de conservação da biodiversidade.

Palavras-chave: Educação ambiental não formal; Plano de manejo; Gestão ambiental; Parque.

\footnotetext{
${ }^{1}$ Mestre em Educação pelo Programa de Pós-Graduação em Educação da Universidade Estadual Júlio de Mesquita Filho (UNESP), campus de Rio Claro, linha de pesquisa em "Educação Ambiental". E-mail: mawick@gmail.com

${ }^{2}$ Atua como docente no Instituto de Física e Química da Universidade Federal de Itajubá (UNIFEI) e no Programa de Pós-Graduação em Ensino de Ciências da mesma instituição. Também está associado, na condição de docente colaborador, ao Programa de Pós-Graduação em Educação da Universidade Estadual Júlio de Mesquita Filho (UNESP), campus de Rio Claro. E-mail: lufesilva@uol.com.br.
} 


\section{Introdução}

Que processos educativos voltados para a temática ambiental são constituídos em Unidades de Conservação? Essa é uma questão que definitivamente tem chamado a nossa atenção. Todavia, nossas tentativas de encontrar possíveis respostas na bibliografia especializada esbarraram em um número reduzido de trabalhos acadêmicos sobre 0 assunto. Entre eles destacamos as dissertações de Toledo (2002), Pivelli (2006), Valenti (2010) e a tese de Saisse (2013).

Em contraposição ao pequeno número de trabalhos acadêmicos voltados à investigação dos processos de educação ambiental (EA) desenvolvidos em ambientes não formais de ensino, há um número significativamente maior de trabalhos que se propõe a investigar processos educativos ocorrendo em ambientes formais de ensino. De acordo com Kawasaki, Matos e Motokane (2006), o número de trabalhos que discutem a educação ambiental no contexto da educação formal é claramente predominante, ao menos nas produções analisadas por esses autores.

Carvalho e Farias (2011), por sua vez, ao elaborarem um balanço da produção científica em educação ambiental pautado nas atas da Associação Nacional de Pós-Graduação e Pesquisa em Educação (ANPEd), da Associação Nacional de Pós-Graduação e Pesquisa em Ambiente e Sociedade (ANPPAS) e do Encontro de Pesquisa em Educação Ambiental (EPEA), entre os anos de 2001 a 2009, também observaram uma predominância de pesquisas em EA no contexto escolar.

Todavia, Kawasaki, Matos e Motokane (2006) indicam que este é um resultado previsível, tendo em vista que temas como a $E A$ em espaços não formais possuem, predominantemente, autores provenientes de Organizações Não Governamentais (ONGs) ou outros órgãos públicos que não a universidade e/ou o sistema educativo formal e que, frequentemente, utilizam outros periódicos e eventos para divulgar seus trabalhos, sendo que estes não possuem, necessariamente, caráter acadêmico.

Diante desse quadro, entendemos ser significativa e necessária a realização de investigações cujo foco esteja centrado nos processos educativos que articulem a temática ambiental em contextos não escolares, especificamente aqueles ocorridos em Unidades de Conservação (UC).

É importante destacar que tanto a EA quanto as UC derivam, em sua origem histórica, do movimento ambientalista. Além disso, apresentam certos objetivos comuns, como por exemplo a tentativa de reversão do quadro de degradação ambiental presente em nossa sociedade. Medeiros, Irving e Garay (2004), ao destacar as UC, acrescentam: "Neste cenário [...] o movimento ambientalista brasileiro, que pregava a criação de áreas protegidas para a preservação da natureza - uma tendência internacional - encontrou terreno fértil" (p. 84). Acerca da educação ambiental, Carvalho, I. (2001) afirma: "[...] parece ser um fenômeno cuja gênese e desenvolvimento estariam mais ligados 
aos movimentos ecológicos e ao debate ambientalista do que propriamente ao campo educacional e à teoria da educação" (p. 46).

Nessa perspectiva, sob que condições (e conjunturas) se estabelece uma ponte entre a EA e as UC?

Sem desconsiderarmos o processo de consolidação das UC e da EA, que se constituíram de forma independente, apontamos que em determinado momento elas se permearam. A EA surgiu oficialmente para a realidade das UC após a promulgação da Lei no 9.795 de 27 de abril de 1999, que institui a Política Nacional de Educação Ambiental (PNEA), momento no qual se estabeleceu o conceito de EA não formal (BRASIL, 1999). A partir de então - e com a promulgação da Lei $n^{0}$ 9.985, de 18 de julho de 2000, que cria e implementa o Sistema Nacional de Unidades de Conservação da Natureza (SNUC) - ficou instituído como objetivo das UC promover a EA de forma a articulá-la aos seus programas de proteção (BRASIL, 2000).

No contexto brasileiro, primeiramente, a EA se instaurou nos órgãos públicos de proteção ao meio ambiente. Lima (2011) destaca que "A EA também se organizou e desenvolveu em outras esferas institucionais ligadas à estrutura governamental de meio ambiente, como é o caso dos parques e das unidades de conservação [...]" (p. 118).

A incorporação da EA aos programas de gestão estabelecidos pelas UC provocou uma série de mudanças de concepção do que sejam áreas protegidas e, consequentemente, do modelo de gestão dessas áreas. Esse processo dependeu de todo um trajeto histórico associado ao momento fundador da criação e ao posterior desenvolvimento de UC. Inicialmente vistos como espaços para recreação e conservação, passam a ser compreendidos e reconhecidos enquanto espaços educativos. Há, portanto, o entendimento de que essas áreas estão voltadas para a proteção dos atributos naturais e socioculturais e que foram ao longo do processo reconhecidas também como espaços educativos.

A princípio entendia-se que o poder/controle das UC deveria estar centralizado no governo, pois isso garantiria a proteção das áreas delimitadas. O modelo de gestão sofreu mudanças ao longo dos anos, impactando diretamente a mudança no campo das políticas ambientais:

[...] tem-se enfatizado a ampliação dos mecanismos de participação dos diversos atores sociais envolvidos com a gestão dos recursos naturais. Depois de um período em que as iniciativas de regulação estiveram fortemente centralizadas junto às instituições governamentais, o cenário das décadas de 1980 e 1990 foi sendo crescentemente marcado pela busca de modelos alternativos de participação da sociedade civil nos processos de tomada de decisão de políticas [...] com caráter ambiental (CUNHA; COELHO, 2010, p.66). 
Maretti et al. (2012) apresentam no Quadro 1 duas perspectivas acerca do modelo de gestão de áreas protegidas, clássico e atual, e elencam algumas das principais modificações ocorridas a traduzir a concepção de área protegida historicamente repensada e redefinida com base em certos valores e princípios.

Quadro 1: Comparação entre os modelos clássico e atual de áreas protegidas.

\section{MODELO CLÁSSICO \\ (COMO AS ÁREAS PROTEGIDAS ERAM)

\begin{abstract}
Áreas reservadas e administradas com intenção de se proteger dos impactos externos (aceitando mais a posição dos visitantes do que das comunidades locais).
\end{abstract}

\section{MODELO ATUAL}

(COMO AS ÁREAS PROTEGIDAS

TÊM SE TORNADO)

Com diferentes ecossistemas, geridas com as comunidades e outros grupos sociais locais, para elas e em alguns casos por elas; e geridas com objetivos também sociais e econômicos, além da conservação e da recreação.

Criadas com maior ênfase nas aparências do que no funcionamento dos sistemas naturais; relacionam-se mais com os remanescentes e menos com processos e com a restauração; implementadas separadamente, uma por uma, e manejadas como 'ilhas', sem atenção ao entorno.

Administradas por governos centrais, ou definidas a partir desses, manejadas por especialistas em recursos naturais e tratadas como uma atividade tecnocrática.
Estabelecidas por razões cientificas, econômicas e culturais, com justificativas mais complexas; relacionam-se também com processos e com reabilitação; concebidas como parte de sistemas (nacionais, regionais e internacionais), redes e conjuntos (mosaicos, corredores, etc.).
Geridas com ou por vários parceiros (diferentes niveis de governos, comunidades locais, indigenas, setor privado, ONGs, etc.), com capacidades múltiplas e como parte de políticas públicas - requerendo sensibilidade, consultas e decisões astutas.
Manejadas de forma reativa, com perspectivas de curto prazo, muito voltadas aos turistas e pouca consideração com outros atores sociais (inclusive as comunidades locais), além de não proceder a consultas e não prestar informaçōes à sociedade.
Geridas com perspectivas de longo prazo, de forma adaptativa, com processos de aprendizagem, com mecanismos participativos e com atenção voltada também para as comunidades locais e suas necessidades.

Fonte: Maretti et al. (2012).

Destas enfatizamos uma das características do modelo de gestão atual: "[...] geridas com perspectivas de longo prazo [...] com processos de aprendizagem, com mecanismos participativos [...]". O intuito era que o modelo brasileiro expressasse a importância da participação da sociedade (e não somente do poder público) também na defesa dos recursos naturais. Diegues 
(2000) dirá que expressar a importância da participação pública nos processos decisórios não é garantia de efetivação da participação na gestão dessas áreas.

Nesse sentido, a EA foi compreendida enquanto um canal de acesso da sociedade à UC, tanto para estimular a participação da sociedade civil na gestão da unidade quanto para garantir o desenvolvimento de processos educativos. Ao englobar a EA enquanto estratégia das UC, Saisse (2013, p.5, grifo nosso) afirma:

\begin{abstract}
Constantemente a educação ambiental é associada às Áreas Naturais Protegidas por estas serem consideradas estratégicas para a conscientização pública sobre as ameaças à perda da biodiversidade e do papel dessas áreas para a conservação. Entre as políticas que ratificam essa relação temos a Lei 9795/1999 que estabelece a Política Nacional de Educação Ambiental, Art. $13^{\circ}[\ldots]$ que o Poder Público, em níveis federal, estadual e municipal incentivará: a sensibilização da sociedade para a importância das unidades de conservação [...] (incisos IV a VI).
\end{abstract}

Vale a pena ressaltar que a Lei no 9.795/99, que dispõe sobre a Política Nacional de Educação Ambiental (PNEA), define a Educação Ambiental não formal como "[...] as ações e práticas educativas voltadas à sensibilização da coletividade sobre as questões ambientais e à sua organização e participação na defesa da qualidade do meio ambiente", e incumbe "[...] aos órgãos integrantes do Sistema Nacional de Meio Ambiente ${ }^{3}$ (SISNAMA) promover ações de educação ambiental integradas aos programas de conservação, recuperação e melhoria do meio ambiente" (BRASIL, 1999, Art. 3ํ). Nessa perspectiva, visam garantir o direito a um meio ambiente ecologicamente equilibrado, conforme determinado em 1988 pela Constituição Federal. Gohn (2006, p. 29) complementa: "Há na educação não-formal [sic] uma intencionalidade na ação, no ato de participar, de aprender e de transmitir ou trocar saberes".

Contudo, de acordo com Quintas (2004), esse seria um conceito evasivo: "[...] pode-se conhecer bastante sobre Educação Ambiental Formal, mas continua-se ignorando o que qualifica a chamada Educação Ambiental Não-Formal [sic]" (p. 116). Visando classificar a EA não formal, "[...] os educadores do IBAMA [Instituto Brasileiro do Meio Ambiente e dos Recursos Naturais Renováveis] preferem qualificar a sua prática a partir do espaço em que ela se produz: o da gestão ambiental pública" (p. 116).

A partir dessas considerações, julgamos essencial a realização de investigações que procurem explicitar os processos de EA que são

\footnotetext{
${ }^{3}$ O SISNAMA foi instituído pela Lei 6.938 , de 31 de agosto de 1981, regulamentada pelo Decreto 99.274, de 6 de junho de 1990, e é constituído pelos órgãos e entidades da União, dos Estados e dos Municípios instituídos pelo Poder Público, responsáveis pela proteção e melhoria da qualidade ambiental.
} 
estruturados em UC. Nesse contexto, traçamos uma linha de raciocínio para delimitar o problema de pesquisa da seguinte forma: que processos de educação ambiental têm sido estruturados em UC? (Figura 1).

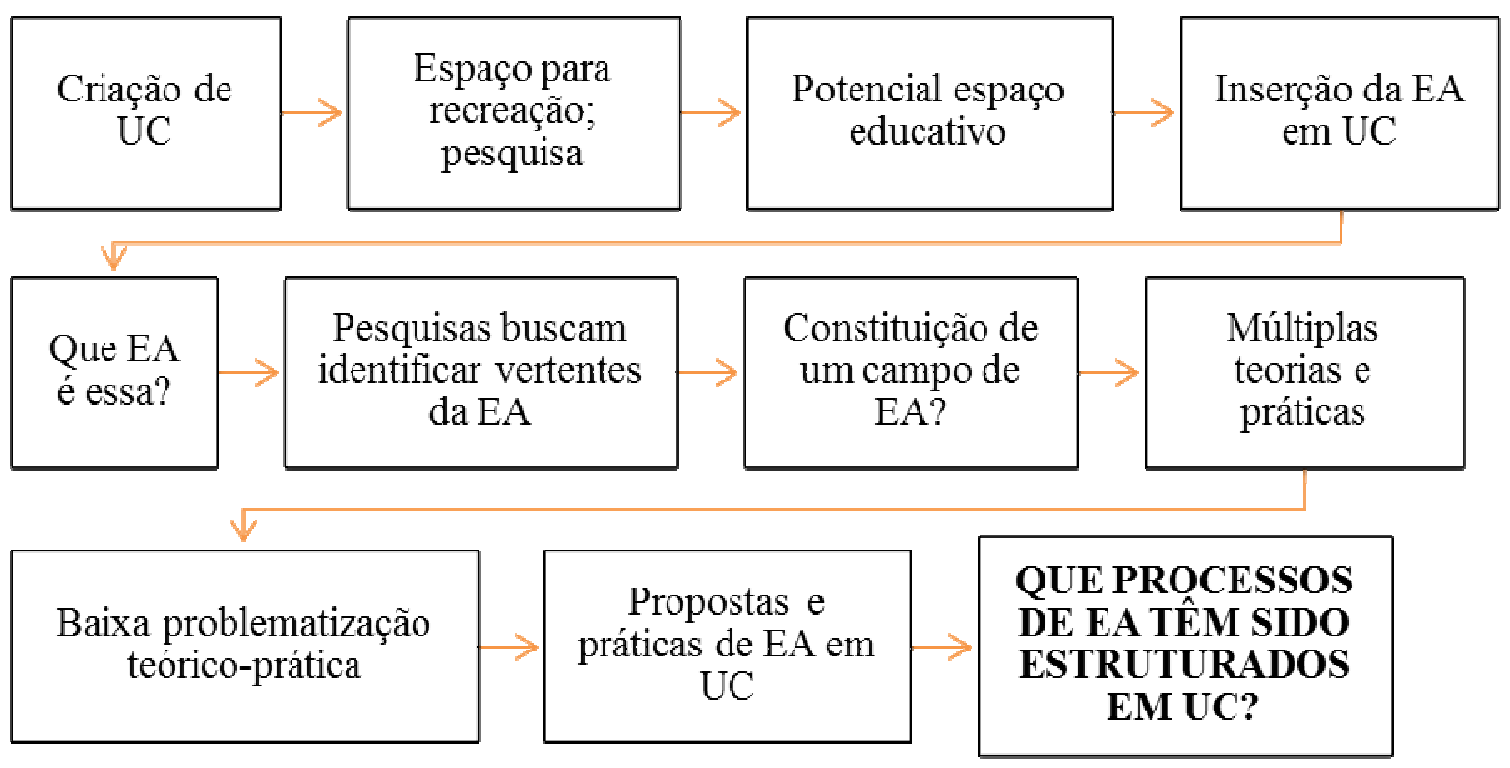

Figura 1: Delineamento do problema de pesquisa.

Fonte: elaboração própria.

Julgamos que esse é um problema de pesquisa amplo. Nesse sentido, este artigo enfoca um aspecto do problema. Nosso interesse, neste trabalho, consiste em apresentar dados que explicitem como são elaboradas as propostas de EA em UC no município de São Paulo, Brasil. Para tanto, nosso intuito é, também, redimensionar a influência que exerce o processo histórico de formalização da EA no planejamento das ações de EA a serem desenvolvidas em UC.

Com base no proposto até aqui, apresentamos a seguir as questões norteadoras desta investigação: que perspectivas da educação ambiental podem ser identificadas nos planos de manejo dos três parques estaduais localizados no município de São Paulo? A partir deste documento técnico que norteia as atividades a serem desenvolvidas pelos diferentes programas de gestão, quais são as atividades de EA planejadas e como elas estão organizadas?

Os critérios que orientaram a delimitação do número de UC a serem investigadas estão explicitados a seguir. 


\section{Critérios para seleção das UC}

Empreendemos uma busca no Cadastro Nacional de Unidades de Conservação (CNUC) ${ }^{4}$, disponível no site do Ministério do Meio Ambiente (MMA), visando identificar as UC localizadas no município de São Paulo, independentemente de sua categoria de proteção e esfera administrativa.

A cidade de São Paulo foi escolhida em razão da localização geográfica e da proximidade entre as UC, que permitiram, dado o curto período de tempo para empreender a coleta e análise dos dados, um acompanhamento mais frequente das atividades educativas realizadas nas UC do município.

De acordo com os resultados encontrados, existem no município quatro Parques Estaduais, dois Parques Municipais ${ }^{5}$, quatro Áreas de Proteção Ambiental (APAs) ${ }^{6}$ e duas Reservas Particulares do Patrimônio Natural (RPPNs) ${ }^{7}$. Das doze UC, cinco delas possuíam plano de manejo aprovado e publicado e estavam, portanto, em conformidade com nosso interesse investigativo. Os últimos consistem de documentos técnicos que estabelecem diretrizes e metas para todas as atividades a serem desenvolvidas pelos diferentes programas de gestão e permitem a identificação das ações de EA implementadas.

$\mathrm{Na}$ etapa final, selecionamos o Parque Estadual da Cantareira (núcleos Engordador e Pedra Grande), Parque Estadual do Jaraguá e Parque Estadual da Serra do Mar (núcleo Curucutu). As outras duas UC em questão - APA Capivari-Monos e Parque Estadual Alberto Löfgren - não foram incluídas no escopo do trabalho em razão de não possuírem um programa permanente de EA formalizado e institucionalizado, muito embora já tivessem sido desenvolvidas ações de EA em anos anteriores.

\section{Procedimentos de coleta e de análise de dados}

Este trabalho se configura como uma pesquisa empírica de natureza qualitativa. De acordo com Bogdan e Biklen (1994), os pesquisadores que se utilizam da pesquisa qualitativa buscam "[...] compreender o processo mediante o qual as pessoas constroem significados e descrever em que consistem estes mesmos significados" (p. 70).

Nesse sentido, Cohen et al. (2001) destacam que a pesquisa qualitativa deve buscar entender a subjetividade do mundo e da experiência humana e ser de natureza indutiva, focando as ações e as intenções dos atores envolvidos na pesquisa.

\footnotetext{
${ }^{4}$ É importante frisar que a busca foi realizada em agosto de 2012, pois as informações do CNUC podem ser atualizadas pelo órgão gestor a qualquer momento.

${ }^{5}$ São eles o Parque Natural Municipal da Cratera de Colônia e Parque Natural Municipal Fazenda do Carmo.

${ }_{7}^{6}$ São elas a APA Capivari-Monos, Bororé-Colônia, Parque e Fazenda do Carmo e Várzea do Tietê.

${ }^{7}$ São elas a RPPN Sítio Curucutu e RPPN Mutinga.
} 
Tendo em vista os objetivos e as UC delimitadas neste trabalho, considerou-se relevante coletar os planos de manejo das três UC selecionadas, realizar observações das atividades desenvolvidas pelos(as) monitores(as) ambientais das UC e entrevistas semiestruturadas com atores dos parques responsáveis pelo planejamento do uso público, pela execução das atividades de EA e pela direção da unidade como um todo (monitor(a) ambiental, coordenador(a) de uso público e gestor(a) da UC).

Foram realizadas ao total dezesseis observações, sendo quatro em cada parque. No caso do PEC, foram no total oito observações empreendidas, considerando quatro em cada núcleo. Ainda, totalizamos doze entrevistas, sendo uma com coordenadora de uso público, três com gestores de cada parque e oito com monitores(as) ambientais, sendo dois(duas) monitores(as) ambientais por parque e núcleo.

Por razões éticas e para preservar a identidade dos atores envolvidos, optamos por indicá-los mediante códigos e números. O código G, para gestores; COORD, para coordenador(a) de uso público e; MA para monitores(as) ambientais. Os números acompanham cada código para distinguir cada ator.

As observações das atividades de EA desenvolvidas pelos três parques foram identificadas pelo código OBS, seguido do número que indica as diferentes monitorias observadas.

Para empreendermos a análise das informações coletadas a partir desses instrumentos, orientamo-nos por algumas perspectivas da Análise de Conteúdo proposta por Bardin (1977). De acordo com Oliveira et al. (2003), o principal objetivo dessa técnica de análise dos dados é prover "indicadores úteis aos objetivos da pesquisa" (p. 16).

As etapas de análise podem ser assim sintetizadas:

1) sistematização das ideias contidas nos documentos que foram submetidos à análise;

2) identificação dos conceitos similares e divergentes ao problema proposto. Foi durante essa fase, portanto, que ocorreu a definição das unidades de sentido e;

3) análise dos dados que derivaram das etapas anteriores e a partir da qual resultou um quadro teórico. Nessa etapa pudemos interpretar e refletir sobre os conceitos que diziam respeito aos objetivos propostos.

Tendo em vista as questões específicas que nortearam esta investigação e o referencial metodológico utilizado para empreender a análise dos dados, apresentamos nas seções seguintes os resultados e reflexões deles decorrentes. 


\section{Os parques estaduais investigados}

Revisitando o conceito de "parques estaduais", estes são definidos como "áreas geográficas delimitadas, dotadas de atributos naturais excepcionais, objeto de preservação permanente, submetidas à condição de inalienabilidade e indisponibilidade no seu todo" (SÃO PAULO, 1986, Art. $1^{\circ}$, Parágrafo $1^{\circ}$ ). A proposta para criação de uma UC pertencente a essa categoria "[...] deve considerar as necessidades de conservação dos ecossistemas naturais, evitando-se o estabelecimento de unidades isoladas que não permitam total segurança para proteção dos recursos naturais renováveis" (SÃO PAULO, 1986, Art. 41) e "[...] devem ser precedidas de estudos demonstrativos das bases técnico-científicas e sócio-econômicas [sic], que justifiquem sua implantação" (SÃO PAULO, 1986, Art. 42).

Os estados de São Paulo, Minas Gerais, Paraná e Rio Grande do Sul são os pioneiros na criação dessa categoria de manejo de UC (MITTERMEIER et al., 2005). São Paulo é também o pioneiro na apresentação de um Regulamento dos Parques Estaduais Paulistas. Conforme destacado por ele, essas áreas "[...] destinam-se a fins científicos, culturais, educativos e recreativos e criados e administrados pelo Governo Estadual, [os parques] constituem bens do Estado destinados ao uso do povo [...]" (SÃO PAULO, 1986, parágrafo $2^{\circ}$ ), cujo principal objetivo é a preservação de ecossistemas.

A seguir, apresentamos um breve histórico de criação dos Parques Estaduais da Cantareira (PEC), do Jaraguá e da Serra do Mar.

Em meados de 1890, visando proteger o maior manancial da Região Metropolitana de São Paulo (RMSP), conhecido como Sistema Cantareira de Águas, e garantir a prestação de importante serviço ambiental - 0 abastecimento de água da cidade de São Paulo -, o Governo do Estado de São Paulo iniciou a desapropriação de diversas fazendas ali instaladas. Primeiramente, as terras foram tombadas como Reserva Florestal, sendo oficializada a criação do Parque por meio do Decreto Estadual ํo 10.228 , em 24 de setembro de 1968 (SÃO PAULO, 2009). Seu primeiro plano de manejo foi lançado no ano de 1977 e revisado mais recentemente no ano de 2009.

O Parque Estadual da Serra do Mar (PESM), a maior Unidade de Conservação do Estado de São Paulo, com 315.390 hectares, foi criado pelo Decreto $n^{0}$ 10.251, de 30 de agosto de 1977, e tinha por finalidade "[...] assegurar integral proteção à flora, à fauna, às belezas naturais, bem como para garantir sua utilização a objetivos educacionais, recreativos e científicos e caracteriza-se por ser uma Unidade de Conservação de proteção integral". Seu último ato legal, o Decreto no 13.313, de 6 de março de 1979, dá nova redação sobre o decreto de criação do PESM (SÃO PAULO, 2006).

Essa UC teve seu plano de manejo elaborado e publicado em 2006, ainda quando era administrada pela Divisão de Reservas e Parques (DRPE) do Instituto Florestal (IF). Em 2007 houve reestruturação dos órgãos ambientais e sua gestão foi transferida à Fundação Florestal (FF). 
Por fim, o Parque Estadual do Jaraguá (PEJ) está constituído em uma área que abrange 492 hectares, sendo esta antigamente uma fazenda. A propriedade foi adquirida pelo Governo do Estado em 1940, sendo criado o Parque Estadual do Jaraguá 21 anos depois pelo Decreto de criação no 38.391 , de 3 de maio de 1961.

No período de 1974 a 2004, visando a construção de um complexo turístico, investiu-se intensamente na infraestrutura destinada ao turismo em massa do PEJ. No fim do período de 2004, após constatado o estado precário da infraestrutura, em função da intensa visitação, a gestão é reavaliada e é transferida à $\mathrm{FF}$ em 2007, que se dedicou nos anos seguintes à normatização da visitação à referida área (SÃO PAULO, 2010). O processo de elaboração do plano de manejo dessa UC teve início em 2003, porém, foi concluído no ano de 2010.

\section{O potencial educativo das UC: objetivos e finalidades da EA nesses espaços}

Apresentamos nesta seção resultados decorrentes da orientação das duas questões específicas propostas para esta investigação, e que nos permitiu:

- identificar a maneira como a gestão dos parques incorporou as recomendações para incluir a EA aos seus programas de gestão;

- compreender a organização da EA dentro do Programa de Uso Público (PUP) e como o último está estruturado e;

- identificar os objetivos e finalidades da educação ambiental estabelecidos pelos três parques.

Em relação ao primeiro tópico listado, a inclusão da educação ambiental tornou-se obrigatória somente a partir da concretização do Sistema Nacional de Unidades de Conservação da Natureza (SNUC), que definiu também como objetivo da categoria "parque" o desenvolvimento de atividades de educação e interpretação ambiental (BRASIL, 2000), muito embora já existisse, por parte de alguns instrumentos legais, a recomendação para que as UC desenvolvessem atividades de cunho educativo (BRASIL, 1944, 1965; SÃO PAULO, 1986).

A incorporação da educação ambiental aos programas de gestão dessas áreas aparece inicialmente atrelada aos objetivos dos parques. A seguir, apresentamos os objetivos mencionados pelos(as) monitores(as) ambientais durante as entrevistas empreendidas e as observações das atividades de EA desenvolvidas (Tabela 1). 
Tabela 1: Objetivos dos parques explicitados a partir das falas dos(as) monitores(as) ambientais dos três Parques Estaduais durante as entrevistas e as monitorias realizadas.

\begin{tabular}{|c|c|c|c|}
\hline AGRUPAMENTO & UNIDADES DE SENTIDO & $\begin{array}{l}\text { ENTREVISTAS } \\
\text { (frequência) }\end{array}$ & $\begin{array}{l}\text { OBSERVAÇÕES } \\
\text { (frequência) }\end{array}$ \\
\hline $\begin{array}{l}\text { Conservação e } \\
\text { Preservação }\end{array}$ & $\begin{array}{c}\text { A finalidade do parque é a } \\
\text { conservação (MA4) }\end{array}$ & 2 & 8 \\
\hline $\begin{array}{l}\text { Educação } \\
\text { ambiental }\end{array}$ & $\begin{array}{c}\text { "Nosso trabalho é de EA. É } \\
\text { de conscientizar as } \\
\text { pessoas." (OBS2) }\end{array}$ & 2 & 3 \\
\hline Pesquisa & $\begin{array}{c}\text { "Quando o parque foi criado, } \\
\text { o objetivo principal [...] era a } \\
\text { pesquisa." (MA7) }\end{array}$ & 1 & 4 \\
\hline Lazer & $\begin{array}{l}\text { "Porque querendo ou não, } \\
\text { aqui é também sim para } \\
\text { lazer, mas não é só isso. } \\
\text { Também tem a parte de } \\
\text { matéria, da cultura, né, que é } \\
\text { o mais importante." (MA1) }\end{array}$ & 1 & 3 \\
\hline Visitação & $\begin{array}{c}\text { "Abrir porta para a visitação" } \\
\text { (OBS5) }\end{array}$ & - & 2 \\
\hline Sensibilização & Sensibilizar (OBS5) & - & 1 \\
\hline Conscientização & $\begin{array}{c}\text { "Nosso papel é conscientizar } \\
\text { vocês. Porque atitudes } \\
\text { ajudam a preservar a mata." } \\
\text { (OBS4) }\end{array}$ & - & 1 \\
\hline Uso Público & “Uso público" (OBS1) & - & 1 \\
\hline
\end{tabular}

Fonte: Dados da pesquisa.

Ao perguntarmos aos(às) monitores(as) sobre os objetivos do Programa de Uso Público ou até mesmo sobre as atividades de EA desenvolvidas, alguns/algumas deles(as) nos forneceram respostas que estavam diretamente relacionadas aos objetivos do parque. Para eles(as), os objetivos variam entre proteger seus recursos naturais e hídricos (MA4; MA7), desenvolver atividades educativas (MA2; MA7), oferecer lazer ao visitante (MA1) e permitir o desenvolvimento de pesquisas (MA7). Nessa perspectiva, entendemos que a $E A$, atualmente, é compreendida enquanto um dos objetivos dos parques.

A partir dos dados expostos na tabela 1, constatamos que os programas de proteção, de uso público e de pesquisa são as grandes referências para os(as) monitores(as) ambientais, uma vez que todos os objetivos contemplados em suas falas, tanto durante as monitorias realizadas com os grupos que acompanhamos quanto durante as entrevistas, foram reafirmados. Ainda assim, outros objetivos foram citados, a saber: "conscientização", "sensibilização", "uso público" e "visitação".

Além desses programas, outros estão previstos nos documentos oficiais desses parques. São eles: proteção aos patrimônios histórico, cultural e natural; visitação, recreação, lazer e educação; pesquisa científica; 
regularização fundiária e; interação socioambiental (PM1; $P M 2 ; \mathrm{PM}^{8}$ ). Faz-se necessário explicitar que atualmente, dentre os programas de gestão propostos para os parques, é o PUP que busca adequar e ordenar a educação ambiental.

Outro resultado que desejamos apresentar é relativo às análises das perspectivas da EA compreendidas nos Programas de Uso Público. Eles são chamados em um dos documentos técnicos de programa de visitação pública, compreendendo atividades de ecoturismo e EA (PM1). De acordo com o PM2 e PM3, seus objetivos são:

Propiciar aos visitantes o contato com a natureza e culturas locais, por meio de experiências recreativas e educativas, motivando-os para práticas conservacionistas e sustentáveis (PM2; PM3).

Para implementá-lo, por sua vez, são traçadas diretrizes e linhas de ação, cujo intuito é alcançar os objetivos propostos. Do total de diretrizes estabelecidas, enfatizamos uma delas, cunhada "Aprimoramento das atividades de Educação Ambiental". Os objetivos da diretriz, contudo, variam de documento para documento.

Embora tenhamos nos empenhado em identificar nos documentos os objetivos específicos concebidos para a EA em cada UC específica, observamos que a maioria deles fazia menção exclusivamente aos objetivos presentes no PUP. Isso se deve, provavelmente, ao fato de as atividades de EA estarem frequentemente associadas ao PUP, cujos objetivos propostos são mais amplos, pois abarcam, além da EA, outras atividades. De acordo com Loureiro (2004), "É por isto, inclusive, que o senso comum muitas vezes acaba vendo-a [a educação ambiental], ainda hoje, como mero meio de apoio em projetos denominados 'ambientais', e não como uma perspectiva paradigmática em educação” (p. 75-6).

Definir minimamente a concepção e os objetivos das atividades de EA parece ser importante para que ela não caia na crítica empreendida por Loureiro (2004), de que as ações de EA sejam caracterizadas enquanto recursos de projetos ecológicos. A despeito disso, identificamos nos documentos passagens que faziam menção aos objetivos da EA. Muito embora ela não esteja organizada dentro de um programa próprio - e por isso atentamos também para algumas características do PUP desenvolvido pelos parques -, observamos que ela possui características específicas e objetivos próprios, que abarcam o terceiro e último tópico proposto para este artigo: os objetivos e as finalidades da EA estabelecidos pelos três parques.

Destacamos, a seguir, alguns trechos retirados do documento que contemplam a concepção de EA para o parque:

${ }^{8}$ Para identificar esses documentos criamos um sistema de códigos representado pela sigla PM, seguido da numeração, para diferenciá-los.

Revbea, São Paulo, V. 10, N 1: 201-220, 2015. 
A perspectiva de uma educação ambiental transversal, entendida como uma estratégia de informação e formação que permeia todas as áreas de conhecimento [...] não está devidamente contemplada atualmente nas ações em andamento da unidade de conservação, visto tem que [sic] sido tratada de modo fragmentado e segmentado (PM1).

Fica bastante claro que:

[Esta] abordagem fragmentária e o isolamento da educação ambiental reduzem sua ação e indicam que, na prática, há a necessidade de avançar em direção a uma educação socioambiental que ultrapasse uma dimensão unicamente conservacionista, mais coerente com o papel das unidades de conservação segundo o SNUC (PM1).

De acordo com os documentos oficiais, a EA visa a promoção de atividades que permitam a reflexão ou a compreensão das relações estabelecidas entre a sociedade e a natureza (PM2; PM3). Um trecho é transcrito para ilustrar a ideia:

[...] um programa de educação e meio ambiente deve promover, prioritariamente, a atividade de reflexão sobre as relações sócio-econômicas [sic] e culturais entre a sociedade e a natureza e o desenvolvimento de atitudes (PM2).

Para complementar, obtivemos informações - com as entrevistas realizadas junto aos monitores, coordenadora de uso público e gestores das UC, e com as observações de algumas ações de monitorias empreendidas que nos possibilitaram analisar a compreensão que esses atores possuem sobre os objetivos e as finalidades da EA para as UC. A seguir apresentamos a tabela 2, que sistematiza essas informações.

Justificativas como "conservação e preservação", "conscientização" e "mudança de comportamentos e atitudes" foram recorrentemente citadas, sendo mencionadas em oito de um total de onze entrevistas. Com relação aos agrupamentos, entendemos que a questão da conservação - enquanto objetivo da EA - parece significar a proteção do território e dos atributos da UC. Além da proteção, questões como valorização da UC pela população e mediação da relação e os possíveis conflitos decorrentes da comunidade do entorno com a UC apareceram nas falas dos gestores. 
Tabela 2: Objetivos e finalidades da EA nas UC de acordo com os monitores e os gestores de três UC localizadas no município de São Paulo.

\begin{tabular}{|c|c|c|}
\hline AGRUPAMENTO & UNIDADE(S) DE SENTIDO & FREQUÊNCIA \\
\hline Conscientização & $\begin{array}{c}\text { "Você tem que criar uma consciência ambiental } \\
\text { para depois fazer com que a pessoa faça uso } \\
\text { adequado do espaço público." (MA8) }\end{array}$ & 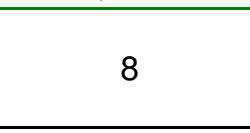 \\
\hline $\begin{array}{l}\text { Conservação e } \\
\text { preservação }\end{array}$ & $\begin{array}{c}\text { "É para eles começarem a entender a importância } \\
\text { de conservar a natureza." (MA5) }\end{array}$ & 8 \\
\hline $\begin{array}{l}\text { Mudar } \\
\text { comportamentos e } \\
\text { atitudes }\end{array}$ & $\begin{array}{c}\text { "Poxa, se você quer passar educação ambiental } \\
\text { para as pessoas, se você quer orientá-la, você } \\
\text { tenta trazer ela para o mais próximo possível do } \\
\text { correto." (MA7) }\end{array}$ & 8 \\
\hline Sensibilização & $\begin{array}{c}\text { "É a sensibilização das pessoas que vem aqui, } \\
\text { com certeza." (MA5) }\end{array}$ & 2 \\
\hline Experiência estética & $\begin{array}{c}\text { "Se despertasse esse lado na pessoa que está } \\
\text { chegando na Unidade, ter contato com a natureza } \\
\text { [...] Primeiro a pessoa tem que ter a sensibilidade } \\
\text { de perceber isso. As vezes você está falando e a } \\
\text { pessoa não está entendendo nada [...] Então se } \\
\text { ela consegue tocar, a unidade chegou na } \\
\text { proposta. O aluno, o visitante vem aqui e tem } \\
\text { contato com a Unidade: 'Isso é muito bonito! O ar } \\
\text { aqui é maravilhoso. O perfume da planta.... Já } \\
\text { valeu." (G2) }\end{array}$ & 2 \\
\hline Visão crítica & $\begin{array}{l}\text { "Você está falando de uma Unidade de } \\
\text { Conservação no mundo de hoje. As pessoas não } \\
\text { tem educação ambiental, elas não são educadas } \\
\text { com a natureza, porque elas entendem que a } \\
\text { natureza não dá nada pra elas, pois muitas vezes } \\
\text { elas acham que é o homem [...] Então no mundo } \\
\text { capitalista é muito difícil você não ter uma } \\
\text { Educação Ambiental em um parque nacional de } \\
\text { conservação. Essa é minha opinião." (MA3) }\end{array}$ & 1 \\
\hline
\end{tabular}

De acordo com os gestores G2 e G3, durante as entrevistas semiestruturadas, a ideia de propor atividades de EA seria uma forma de agregar o conhecimento sobre o meio ambiente (para que os visitantes entendessem a importância de "conservar e preservar"):

[...] mas o foco é esse mesmo do conservacionismo, de ter acesso às Unidades [...] (G2).

Você trabalha isso através de uma educação para o meio ambiente (G3).

Alguns dos objetivos citados já haviam sido reproduzidos em pesquisas realizadas anteriormente, a saber: "proteção da unidade de conservação";

\footnotetext{
${ }^{9}$ Os agrupamentos estão organizados por ordem decrescente de frequência absoluta.
}

Revbea, São Paulo, V. 10, Nº 1: 201-220, 2015. 
"proporcionar o contato direto com a natureza" e; "promoção da conservação e valorização das UC" (DIAS, 2008; TOLEDO, 2002).

$\mathrm{Na}$ literatura especializada sobre EA é frequente encontrarmos considerações acerca de um processo educativo mais direcionado para a preservação e a conservação. Essa compreensão de educação está imbricada no momento fundador do movimento ambientalista (VIOLA, 1992), cuja preocupação era voltada para a importância de preservar os ecossistemas naturais. Layrargues e Lima (2011), por exemplo, afirmam que:

Isso [ocorreu] provavelmente porque a face mais visível da crise ambiental em seu princípio foi a destruição da natureza e porque as ciências ambientais ainda não estavam maduras 0 suficiente para compreender a complexidade das relações entre sociedade e natureza. Os problemas ambientais eram, em grande medida, percebidos como efeitos colaterais de um projeto inevitável de modernização, passíveis de serem corrigidos, ora pela difusão de informação e de educação sobre o meio ambiente [...] (p. 5, grifo nosso).

A coordenadora de uso público, por sua vez, tece comentários acerca da sensibilização que, para ela, consiste no principal objetivo da EA:

O principal objetivo é sensibilizar. [...] O que se insere dentro da educação ambiental são as atividades que são desenvolvidas em prol do público na questão da sensibilização. Eu nem falo da conscientização, porque conscientizar é um processo. Eu não posso ter a petulância de achar que uma pessoa vai vir aqui e ela vai sair daqui conscientizada. Não! O máximo que a gente vai fazer naquele tempinho que a pessoa tem aqui é sensibilizar ela. Criar nela um click, um start. [...] fazer com que as pessoas cheguem aqui, entendam o que é esse lugar [...] qual a sua importância. [...] E saírem sensibilizadas em relação ao que é preservação e conservação de uma área que é extremamente rica, biodiversa. [...] Se for um trabalho a longo prazo, muito melhor. Vai enraizar muito mais as pessoas. Mas, como nosso trabalho é $10 \%, 5 \%$ do que a pessoa vive na vida dela, então acho que nosso papel como unidade é sensibilizar e demonstrar o que somos. [...] Não adianta a gente falar que vai mudar o mundo. A gente não vai mudar (COORD1).

Por fim, é interessante destacarmos uma tendência presente na fala desses atores. Frequentemente eles reconhecem que a EA pode possibilitar alcançar alguns dos objetivos propostos para o parque, estes, por sua vez, mais amplos e que incidem sobre a variedade de programas de gestão 
estruturados nos planos de manejo. Nessa perspectiva, há uma sobrevalorização acerca do papel da EA, considerada de forma contraditória um objetivo do parque e, simultaneamente, o caminho para atingir outros objetivos propostos, também para o parque. Assim, a EA, desse ponto de vista, não se restringe às questões de cunho educativo. Pelo contrário, está vinculada e articulada aos objetivos de conservação e proteção, isto é, às atividades voltadas para garantir o acesso às UC, difundir informações, agregar conhecimento sobre o meio ambiente e valorizar o papel desempenhado pelas UC.

Entendemos que algumas das atividades mencionadas poderiam ser viabilizadas por meio de outros programas, como, por exemplo, de turismo, fiscalização, uso público e até mesmo proteção. No entanto, essa tendência se reflete em uma postura adotada por alguns atores dos parques, em que é atribuído mais peso às reais possibilidades da EA. Algumas considerações a respeito destas atividades foram feitas:

Às vezes, parece que a gente tem uma carga enorme de responsabilidade. Como se a gente fosse consertar a unidade inteira, todos os conflitos e problemas a partir da educação ambiental. Quem dera fosse assim! (COORD1).

Esse depoimento explicita a questão já discutida por autores como Barcelos (2009), Carvalho, L. (2006) e Meyer (1991). Esta última nos diz: "A educação ambiental não é a solução 'mágica' para os problemas ambientais [...]" (p. 41). Assim, a EA não deve ser encarada como solução para resolver todos os problemas das UC.

Refletindo sobre alguns dos objetivos específicos que se deseja alcançar com a inclusão da EA nas UC e considerando os interesses ideológicos da criação dessas áreas, as ações de EA implementadas parecem seguir quase que um caminho "natural". Afinal, se julgamos que tais áreas existem para tentar reverter o quadro de degradação e destruição ambiental, estabelecer objetivos que visam mitigar ações de degradação e contribuir com o processo de valorização das UC nos parece coerente com a sua proposta de criação.

No entanto, a própria constituição de novas UC ou a permanência das UC já existentes é um diagnóstico de que a lógica estruturante da relação entre sociedade e natureza segue na mesma direção da lógica criticada pelo movimento ambientalista em meados da década de 1960. Ainda estão previstas medidas mitigadoras que regulam o acesso às áreas protegidas $e$, consequentemente, aos recursos naturais.

Em nosso entendimento, a EA em UC deveria propor e promover uma reflexão mais complexa, que abarcasse a real compreensão do que significa constituir uma UC e quais os mecanismos de participação da sociedade civil no processo. 
Apesar de todas as considerações aqui empreendidas, ainda assim são realizadas ações de EA que buscam promover o reconhecimento e a valorização das UC enquanto locais que desempenham importante papel para assegurar a proteção da natureza.

\section{Conclusões}

Os parques estaduais apresentam como pilares de atuação a proteção, a pesquisa e o uso público. Este último foi pautado a partir da necessidade evidenciada pelas UC, dentre outras, de construção de princípios, valores e posturas voltados à conservação da biodiversidade e a despertar a consciência crítica para a necessidade de conservação. Visando alcançar essa finalidade de reconhecimento e de valorização dessas áreas enquanto locais de conservação e preservação de seus atributos naturais e culturais pela população, foi proposto o desenvolvimento de ações de EA como uma das diretrizes do PUP.

Ao incorporar processos educativos aos objetivos do parque, e como reflexo das indefinições e fragilidade teórico-metodológica da EA nos documentos oficiais, muitos dos objetivos gerais estabelecidos para o parque foram atribuídos também à EA pelos responsáveis pela execução e acompanhamento das ações educativas. Esse seria um indicativo de que a EA vem sendo encarada pelos parques como um ponto de apoio, e não necessariamente uma perspectiva paradigmática em educação, sendo a ela incumbida a tarefa de resolução de problemas enfrentados pela gestão do parque.

Consideramos, portanto, que a gestão dos parques deve decidir, independentemente dos princípios da EA formal, qual processo educativo é adequado para ser desenvolvido em UC e qual permitirá alcançar os objetivos propostos pelos parques. Ou seja, o processo educativo deve consolidar a identidade do parque e da EA que se pretende desenvolver. Isso porque às UC são atribuídas distintas tarefas e distintos papéis, sendo a EA apenas uma das inúmeras atividades empreendidas pelas UC.

O modelo de gestão das UC adotado nos dias de hoje para estruturar e desenvolver a EA é diretamente influenciado pelo contexto histórico que concebeu as UC e a EA. Diante desse contexto, convém, em futuras investigações, compreender: Que discursos político-ideológicos estão presentes nas UC? O que se entende por EA em UC? Quais são os pressupostos teórico-metodológicos que orientam essas práticas educativas?

Especificamente, a EA estruturada em UC está imbricada no processo histórico de constituição do campo, muito mais vinculada às demandas do campo ambiental do que ao campo educativo. A dificuldade em compreender a EA fora dos movimentos ecológicos, conforme já propunha Carvalho, I. (2008), parece refletir a existência de uma preocupação com as questões ambientais e não necessariamente com as questões educativas. Dessa forma, não vem 
sendo devidamente explorado o seu potencial educativo para promover discussões acerca das relações estabelecidas entre sociedade e natureza.

No entanto, as UC, enquanto organizadoras das ações de EA, devem assumir a responsabilidade pelos processos educativos não formais e definir uma linha de atuação, que parece já ter sido traçada: as ações de EA estão voltadas para a resolução de problemas internos às $U C$ e a valorização quanto ao papel dessas áreas para a conservação da biodiversidade. Afinal, não podemos simplesmente desconsiderar que esses espaços, embora tenham sofrido um processo de reconhecimento e valorização como espaço educativo, ainda primam pela conservação.

\section{Agradecimentos}

À Fundação de Amparo à Pesquisa do Estado de São Paulo (FAPESP), pelo apoio financeiro à pesquisa; à Universidade Estadual Paulista Júlio de Mesquita Filho (UNESP), campus de Rio Claro, por tornar possível o mestrado da autora.

\section{Referências}

BARCELOS, V. Educação ambiental: sobre princípios, metodologias e atitudes. 2. ed. Petrópolis, RJ: Vozes, 2009. (Coleção Educação Ambiental).

BARDIN, L. Análise de Conteúdo. Tradução: Luís Antero Reto e Augusto Pinheiro. Lisboa: Edições 70, 1977.

BOGDAN, R.; BIKLEN, S. Investigação qualitativa em educação: uma introdução à teoria e aos métodos. Portugal: Porto Editora, 1994.

BRASIL. Decreto Federal no 16.677, de 29 de setembro de 1944. Aprova o Regimento do Serviço Florestal do Ministério da Agricultura. Diário Oficial da União. Brasília, DF, 02 out. 1944.

BRASIL. Lei no 4.771, de 15 de setembro de 1965. Institui o novo Código Florestal. Diário Oficial da União. Brasília, DF, 16 set. 1965.

BRASIL. Lei no 9.795, de 27 de abril de 1999. Dispõe sobre a educação ambiental, institui a Política Nacional de Educação Ambiental e dá outras providências. Diário Oficial da União. Brasília, DF, 28 abr. 1999.

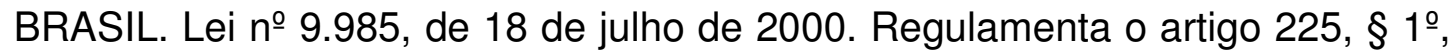
incisos I, II, III, VII da Constituição Federal, institui o Sistema Nacional de Unidades de Conservação - SNUC. Diário Oficial da União. Brasília, DF, 19 jul. 2000.

CARVALHO, I.C.M. Educação Ambiental e Movimentos Sociais: elementos para uma história política do campo ambiental. Educação Teoria e Prática, Rio Claro, UNESP, v. 9, n. 16/17, p. 46-56, 2001.

CARVALHO, I.C.M. A educação ambiental no Brasil. Salto para o futuro. Boletim 01, mar. 2008. 
CARVALHO, I.C.M.; FARIAS, C.R.O. Um balanço da produção científica em educação ambiental de 2001 a 2009 (ANPEd, ANPPAS e EPEA). Revista Brasileira de Educação, Rio de Janeiro: ANPEd, v. 16, n. 46, p. 119-134, jan/abr. 2011.

CARVALHO, L.M. A temática ambiental e o processo educativo: dimensões e abordagens. In: CINQUETTI, H. C. S.; LOGAREZZI, A. (Orgs.). Consumo e resíduos: fundamentos para o trabalho educativo. São Carlos: EdUFSCAR, 2006, p. 19-41.

COHEN, L; MANION, L.; MORRISON, K. Reserch methods in education. London: Routledge Falmer, 2001.

CUNHA, L.H.H.; COELHO, M.C.N. Política e gestão ambiental. In: CUNHA, S. B.; GUERRA, A. J. T. (Orgs.). A questão ambiental: diferentes abordagens. 6. ed. Rio de Janeiro: Bertrand Brasil, 2010, p. 42-80.

DIAS, C.M. Poder público, processo educativo e população: o caso da Estação Ecológica de Angatuba, SP, Brasil. 2008. 167f. Dissertação (Mestrado em Educação) - Universidade Estadual Paulista "Júlio de Mesquita Filho", Rio Claro.

DIEGUES, A.C. O mito moderno da natureza intocada. 3. ed. São Paulo: Hucitec, Núcleo de Apoio à Pesquisa sobre Populações Humanas e Áreas Úmidas Brasileiras, USP, 2000.

GOHN, M.G. Educação não-formal, participação da sociedade civil e estruturas colegiadas nas escolas. Ensaio: aval. pol. públ. Educ., Rio de Janeiro: Fundação Cesgranrio; Autores associados, v.14, n.50, p.27-38, jan./mar. 2006.

KAWASAKI, C.S.; MATOS, M.S.; MOTOKANE, M.T. O perfil do pesquisador em educação ambiental: elementos para um estudo sobre a constituição de um campo de pesquisa em educação ambiental. Pesquisa em Educação Ambiental, Ribeirão Preto: UNESP, v. 1, n. 1, p. 111-140, jul/dez. 2006.

LAYRARGUES, P.P.; LIMA, G.F.C. Mapeando as macro-tendências políticopedagógicas da educação ambiental contemporânea no Brasil. In: ENCONTRO PESQUISA EM EDUCAÇÃO AMBIENTAL, 6., 2011, Ribeirão Preto. Anais... Ribeirão Preto: USP, 4-7, set. 2011. p. 1-15.

LIMA, G.F.C. Educação ambiental no Brasil: Formação, identidades e desafios. Campinas: Papirus, 2011.

LOUREIRO, C.F.B. Educação ambiental transformadora. In: LAYRARGUES, P. P. (Org.). Identidades da educação ambiental brasileira. Brasília: MMA, 2004, p. 65-84.

MARETTI, C.C.; CATAPAN, M.I.S.; ABREU, M.J.P.; OLIVEIRA, J.E.D. Áreas protegidas: definições, tipos e conjuntos. Reflexões conceituais e diretrizes para gestão. In: CASES, M.O. (Org.). Gestão de Unidades de Conservação: compartilhando uma experiência de capacitação. Brasília: WWF-Brasil/IPÊInstituto de Pesquisas Ecológicas, 2012. 
MEDEIROS, R; IRVING, M.; GARAY, I. A Proteção da Natureza no Brasil: evolução e conflitos de um modelo em construção. Revista de Desenvolvimento Econômico, Salvador: UNIFACS, v.6, n.9, p.83-93, 2004.

MEYER, M.A.A. Educação ambiental: uma proposta pedagógica. Em Aberto, Brasília: INEP, v. 10, n. 49, p. 41-46, jan./mar. 1991.

MITTERMEIER, R.A.; FONSECA, G.A.B.; RYLANDS, A.B.; BRANDON, K. Uma breve história da conservação da biodiversidade no Brasil. Megadivesidade, Belo Horizonte: Conservation International do Brasil, v. 1, n. 1, p. 14-21, jul. 2005.

OLIVEIRA, E.; ENS, R. T.; ANDRADE, D. B. S. F.; MUSIS, C. R. Análise de conteúdo e pesquisa na área da educação. Revista Diálogo Educacional, Curitiba, PUC-PR: Editora Universitária Champagnat, v. 4, n. 9, p. 11-27, maio/ago. 2003.

PIVELLI, S.R.P. Análise do Potencial Pedagógico de Espaços Não Formais de Ensino para o desenvolvimento da biodiversidade e sua conservação. 2006. Dissertação (Mestrado em Educação) - Universidade de São Paulo.

QUINTAS, J.S. Educação no processo de gestão ambiental: uma proposta de educação ambiental transformadora e emancipatória. In: LAYRARGUES, P. P. (Org.). Identidades da educação ambiental brasileira. Brasília: MMA, 2004, p. 113-140.

SAISSE, M.V. Sentidos e práticas da educação ambiental no Brasil: as unidades de conservação como campo de disputa. In: ENCONTRO PESQUISA EM EDUCAÇÃO AMBIENTAL, 7., 2013, Rio Claro. Anais... Rio Claro: UNESP, 7-10, jul. 2013. p. 1-16.

São Paulo (Estado). Decreto no 25.341 de 4 de junho de 1986. Aprova o Regulamento dos Parques Estaduais Paulistas. Diário Oficial do Estado (DOE). São Paulo, SP, 05 jun. 1986.

São Paulo (Estado). Secretaria do Meio Ambiente, Fundação Florestal. Parque Estadual da Serra do Mar: Plano de manejo. São Paulo, 2006.

São Paulo (Estado). Secretaria do Meio Ambiente, Fundação Florestal. Parque Estadual da Cantareira: Plano de manejo. São Paulo, 2009.

São Paulo (Estado). Secretaria do Meio Ambiente, Fundação Florestal. Parque Estadual do Jaraguá: Plano de manejo. São Paulo, 2010.

TOLEDO, R.F. Educação ambiental em Unidades de Conservação do Estado de São Paulo. 2002. 169 f. Dissertação (Mestrado em Saúde Pública) Universidade de São Paulo, São Paulo.

VALENTI, M.W. Educação ambiental e biodiversidade em unidades de conservação: mapeando tendências. 2010. 97 f. Dissertação (Mestrado em Ecologia e recursos naturais) - Universidade Federal de São Carlos.

VIOLA, E. O movimento ambientalista no Brasil (1971-1991): da denúncia e conscientização pública para a institucionalização e o desenvolvimento sustentável. In: FUKS, M.; GOLDENBERG, M. (Coord.). Ecologia, ciência e política. Rio de Janeiro: Revan, 1992. 